\title{
Antidermatophytic Properties of Ar-Turmerone, Turmeric Oil, and Curcuma longa Preparations
}

\author{
Mukda Jankasem, ${ }^{1}$ Mansuang Wuthi-udomlert, ${ }^{2}$ and Wandee Gritsanapan ${ }^{1}$ \\ ${ }^{1}$ Department of Pharmacognosy, Faculty of Pharmacy, Mahidol University, 447 Sri-Ayudthaya Road, Ratchathewi, \\ Bangkok 10400, Thailand \\ ${ }^{2}$ Department of Microbiology, Faculty of Pharmacy, Mahidol University, 447 Sri-Ayudthaya Road, Ratchathewi, \\ Bangkok 10400, Thailand
}

Correspondence should be addressed to Wandee Gritsanapan; wandee.gri@mahidol.ac.th

Received 28 May 2013; Accepted 28 July 2013

Academic Editors: M. Ericson, E. Pasmatzi, and K. Saga

Copyright (C) 2013 Mukda Jankasem et al. This is an open access article distributed under the Creative Commons Attribution License, which permits unrestricted use, distribution, and reproduction in any medium, provided the original work is properly cited.

\begin{abstract}
Curcuma longa L. or turmeric of the family Zingiberaceae is widely used in Thai traditional medicines for the treatment of rash, itching, tinea, and ringworm. Previous studies on turmeric oil reported effective antifungal activity against dermatophytes, a group of fungi that causes skin diseases. In this study, turmeric creams containing 6 and $10 \% \mathrm{w} / \mathrm{w}$ turmeric oil were prepared and tested against clinical strains of dermatophytes using broth dilution technique. Minimum fungicidal concentrations of 6 and $10 \% \mathrm{w} / \mathrm{w}$ turmeric creams were found to be $312 \mu \mathrm{g} / \mathrm{mL}$. Ar-turmerone, a major compound separated from turmeric oil, promoted more effective antidermatophytic activity with the MICs of $1.56-6.25 \mu \mathrm{g} / \mathrm{mL}$, compared to $3.90-7.81 \mu \mathrm{g} / \mathrm{mL}$ of standard ketoconazole. The results indicated that $6 \% \mathrm{w} / \mathrm{w}$ turmeric oil in the cream was suitable to be formulated as antidermatophytic preparation. Further research should be done on long-term chemical and antifungal stabilities of the preparation.
\end{abstract}

\section{Introduction}

Dermatophytosis (tinea or ringworm) is a prevalent form of fungal infections found in Thailand because of the tropical climate. The infection is caused by a group of keratinophilic fungi called dermatophytes. Fungi commonly involved are of the genera Trichophyton, Microsporum, and Epidermophyton. Dermatophytosis can transfer from soil and animals to humans and cause infection on many parts of the body $[1,2]$. Historically, Thai traditional medicines containing Curcuma longa have been used for the treatment of dermatophytes. The dry powdered rhizome is mixed with a small volume of water and the mixture is applied onto infected skin [3].

C. longa L. or turmeric is a well-known medicinal plant of the family Zingiberaceae [4]. It has been used for the treatment of skin diseases, rash, itching, tinea and ringworm. Turmeric is a perennial herb with thick and ellipsoidovate rhizome with orange cortex inside. It is cultivated easily, wildly distributed in Thailand and other tropical and subtropical countries, and is also famous as a spice and coloring agent [5]. Medicinal uses of the rhizomes arise from volatile oil as a carminative and antifungal activity and yellow curcuminoids for antioxidative and anti-inflammatory properties. Active constituents in turmeric volatile oil are turmerone, atlantone, and zingiberone [6, 7]. Turmeric oil isolated from turmeric rhizome possesses effective antifungal activity against dermatophytes $[8,9]$. The creams containing $3-8 \% \mathrm{w} / \mathrm{w}$ turmeric oil showed similar antidermatophytic activity $[10]$.

To determine a suitable concentration of turmeric oil in a cream preparation, turmeric creams containing 6 and $10 \% \mathrm{w} / \mathrm{w}$ of turmeric oil were formulated and determined in this study for their antidermatophytic activities. The activities of turmeric oil and ar-turmerone, a major compound in the oil, were also determined and compared. The results will be useful for the development of appropriate turmeric cream as an alternative antidermatophytotic preparation.

\section{Materials and Methods}

2.1. Plant Materials. Turmeric rhizomes were purchased from a local market in Bangkok in April 2009. The sample 
TABLE 1: Average MICs and MFCs of turmeric oil, Ar-turmerone, $6 \%$ and $10 \% \mathrm{w} / \mathrm{w}$ turmeric creams, cream base, ketoconazole, and Daktarin cream solution.

\begin{tabular}{|c|c|c|c|c|c|c|c|c|}
\hline \multirow{2}{*}{ Tested samples } & \multicolumn{4}{|c|}{$\operatorname{MICs}(\mu \mathrm{g} / \mathrm{mL})$} & \multicolumn{4}{|c|}{$\operatorname{MFCs}(\mu \mathrm{g} / \mathrm{mL})$} \\
\hline & T. rubrum & T. mentagrophytes & M. gypseum & E. floccosum & T. rubrum & T. mentagrophytes & M. gypseum & E. floccosum \\
\hline Turmeric oil & 1.56 & 6.25 & 6.25 & 1.56 & 3.12 & 6.25 & 6.25 & 1.56 \\
\hline Ar-turmerone & 3.90 & 7.81 & 7.81 & 3.90 & 62 & 125 & 62 & 31.25 \\
\hline $6 \% \mathrm{w} / \mathrm{w}$ turmeric cream & 156 & 312 & 312 & 78 & 312 & 312 & 312 & 156 \\
\hline $10 \% \mathrm{w} / \mathrm{w}$ turmeric cream & 78 & 156 & 156 & 78 & 312 & 312 & 312 & 78 \\
\hline Cream base & 2500 & 2500 & 2500 & 2500 & 2500 & 2500 & 2500 & 2500 \\
\hline Ketoconazole & 6.25 & 12.50 & 25 & 12.50 & 25 & 12.50 & 25 & 6.25 \\
\hline Daktarin & 54.68 & 54.68 & 54.68 & 54.68 & 54.68 & 54.68 & 54.68 & 54.68 \\
\hline
\end{tabular}

was identified by Dr. Wandee Gritsanapan, and the voucher specimen (WCL0409) was kept at Department of Pharmacognosy, Faculty of Pharmacy, Mahidol University. The fresh rhizomes were cleaned and sliced into small pieces, dried in a hot air oven at $60-80^{\circ} \mathrm{C}$ for 48 hours, and then ground into moderate powder. Turmeric dried powder was extracted by water distillation for 60 hours to obtain volatile turmeric oil which was stored in a closed container, protected from light in a refrigerator $\left(4^{\circ} \mathrm{C}\right)$ until used.

\subsection{Extraction and Separation of Ar-Turmerone from Turme-} ric Oil. Ar-turmerone was separated from turmeric oil by preparative TLC (silica gel $60 \mathrm{GF}_{254}$, hexane: ethyl acetate $97: 3$ ). The separated compound was purified and identified by GC-MS [11].

2.3. Preparation of Turmeric Cream. Oil in water turmeric creams was prepared by two-phase system containing 6 and $10 \% \mathrm{w} / \mathrm{w}$ turmeric oil. Both creams were separately kept in foam tubes protected from light until used.

\subsection{Antifungal Activity Assays}

2.4.1. Inoculum Preparation. Clinical strains (provided by Institute of Dermatology, Bangkok) of T. mentagrophytes, $T$. rubrum, E. floccosum, and M. gypseum were isolated, cultured on Sabouraud dextrose agar (Himedia, Mumbai, India), and incubated at room temperature for 7-10 days to obtain active growing cultures.

\subsubsection{Determination of Minimum Inhibitory Concentration} (MIC). Turmeric oil, Ar-turmerone, and $6 \%$ and $10 \% \mathrm{w} / \mathrm{w}$ turmeric creams were tested for their antifungal susceptibility by broth microdilution assay in accordance with the Clinical and Laboratory Standard Institute guideline in the M38-A9 document on filamentous fungi [12] with some modifications. Briefly, in a U-shaped 96-well microliter plate (Thermo Fisher Scientific, NY, USA), each well was filled with $100 \mu \mathrm{L}$ of twofold serially diluted sample and $100 \mu \mathrm{L}$ of spore suspension of each tested organism. The final concentration of inoculum was adjusted to 0.4 to $5 \times 10^{4} \mathrm{CFU} / \mathrm{mL}$. Each sample was done in triplicate, while growth control of each strain was filled with $200 \mu \mathrm{L}$ of the inoculums. Cream base was used as a negative control, while ketoconazole and miconazole nitrate cream solution (Daktarin, $70 \mathrm{mg} / \mathrm{mL}$ ) were used as positive controls. The MICs, the lowest concentration of the sample that shows no visible growth, after incubation at $28^{\circ} \mathrm{C}$ for approximately $72-96$ hours (or indicated by growth control as the end point) of turmeric oil, ar-turmerone, $6 \%$ and $10 \% \mathrm{w} / \mathrm{w}$ turmeric creams, ketoconazole, and Daktarin cream solution were determined. The minimum fungicidal concentrations (MFCs), defined as the lowest concentration that prevent the fungal growth on the solid medium, were also investigated by subculturing the MICs of each sample onto a new SDA plate and incubated at $28^{\circ} \mathrm{C}$ for approximately $72-96$ hours or indicated by growth control as the end point.

\section{Results and Discussion}

By water distillation, the yield of turmeric oil from the dried rhizomes was $6.3 \% \mathrm{v} / \mathrm{w}$. MICs of turmeric oil and cream base against all tested dermatophytes were 1.56-6.25 and $2500 \mu \mathrm{g} / \mathrm{mL}$, respectively. Turmeric oil possesses higher antifungal activity than cream base, indicative of the effective and active constituent in turmeric cream preparations. MICs of 6 and $10 \% \mathrm{w} / \mathrm{w}$ turmeric creams were found to be $78-$ 312 and $78-156 \mu \mathrm{g} / \mathrm{mL}$, respectively while MICs of Daktarin cream solution was $54.68 \mu \mathrm{g} / \mathrm{mL}$. MICs of $10 \% \mathrm{w} / \mathrm{w}$ turmeric cream proved more effective than the $6 \% \mathrm{w} / \mathrm{w}$ cream, but MFCs of the both creams expressed relatively equal activity (Table 1). The major compound in turmeric oil, identified as Ar-turmerone, promoted effective antidermatophytic activity against all dermatophytes with MICs of $3.90-7.81 \mu \mathrm{g} / \mathrm{mL}$, which is lower than the MIC values of standard ketoconazole at $6.25-25 \mu \mathrm{g} / \mathrm{mL}$ as shown in Table 1 .

This study reveals that turmeric creams exhibits antifungal activity and is effective against dermatophytes. This is confirmative of the ethnopharmacological use of this medical plant to treat skin diseases, especially tinea and ringworm. As a result, the $6 \% \mathrm{w} / \mathrm{w}$ turmeric cream is suitable as an alternative antidermatophytic preparation and could be subjected to further development.

\section{Conclusions}

Ar-turmerone, a major compound in turmeric oil, showed effective antidermatophytic activity. It could be used as an active marker for quality assessment of turmeric oil and active ingredient in turmeric creams and other finished antifungal 
products. The turmeric cream with $6 \% \mathrm{w} / \mathrm{w}$ turmeric oil was suitable for further development as an alternative antidermatophytic preparation. All samples have effective antifungal activity against tested dermatophytes, especially against $T$. rubrum, a common dermatophyte which is widely spread throughout the world. However, further research on longterm physical, chemical and antifungal activity stabilities of the turmeric cream should be done to find the optimum storage condition. The clinical trial of the cream could also be tested on the affected patients to explore the practicality of the cream and the possibility of commercial development.

\section{Conflict of Interests}

The authors do not have any direct financial relation with any commercial identity mentioned in their paper that might lead to a conflict of interests.

\section{Acknowledgments}

This project is part of the Master thesis of Mahidol University, financially supported by the Thailand Research Fund (TRF) with office of Small and Medium Enterprises Promotion (OSMEP) and the Thai Traditional Medicine Development Foundation, Ministry of Health, Thailand.

\section{References}

[1] D. Greenwood, Microbiology, A Guide To Microbiology Infections: Pathogenesis, Immunity, LaboraTory Diagnosis and Control, Churchill Livingstone, Philadelphia, Pa, USA, 17th edition, 2007.

[2] J. W. Rippon, Medical Mycology-the Pathogenic Fungi and the Pathogenic Actinomycetes, W.B. Saunders Company, Philadelphia, Pa, USA, 3rd edition, 1988.

[3] W. Wutthithamavet, Thai Traditional Medicine,", Odean Store Press, Bangkok, Thailand, 1997.

[4] T. Smitinand, Thai Plant Names, The Forest Herbarium, Royal Forest Department, Bangkok, Thailand, 2001.

[5] V. A. Jirawongse, Thai Herbal Pharmacopoeia, vol. 1, Prachachon, Bangkok, Thailand, 1995.

[6] A. Y. Leung and S. Foster, Encyclopedia of Common Natural Ingredients Used in Food, Drugs, and Cosmetics, John Wiley \& Sons, New York, NY, USA, 1996.

[7] W. Pothitirat and W. Gritsanapan, "Variation of bioactive components in Curcuma longa in Thailand," Current Science, vol. 91, no. 10, pp. 1397-1400, 2006.

[8] A. Apisariyakul, N. Vanittanakom, and D. Buddhasukh, "Antifungal activity of turmeric oil extracted from Curcuma longa (Zingiberaceae)," Journal of Ethnopharmacology, vol. 49, no. 3, pp. 163-169, 1995.

[9] M. Wuthi-udomlert, W. Grisanapan, O. Luanratana, and W. Caichompoo, "Antifungal activity of Curcuma longa grown in Thailand," Southeast Asian Journal of Tropical Medicine and Public Health, vol. 31, no. 1, pp. 178-182, 2000.

[10] P. Pitakvongsaporn, The study of antifungal activity stability and skin irritation of turmeric oil [M.S. thesis], Mahidol University, Bangkok, Thailand, 2000.
[11] R. P. Adams, Identification of Essential Oil Components by Gas Chromatography/ Mass Spectrometry, Allured, Carol Stream, Ill, USA, 4th edition, 2007.

[12] Clinical and Laboratory Standard Institute, Reference Method For Broth Dilution Antifungal Susceptibility Testing of Filamentous Fungi, Approved Standard M38-A9, Clinical and Laboratory Standards Institute, Wayne, Pa, USA, 2nd edition, 2008. 


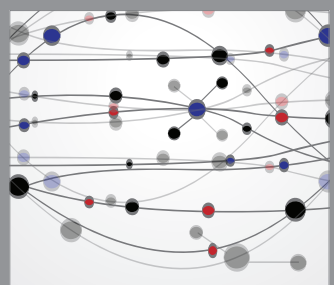

The Scientific World Journal
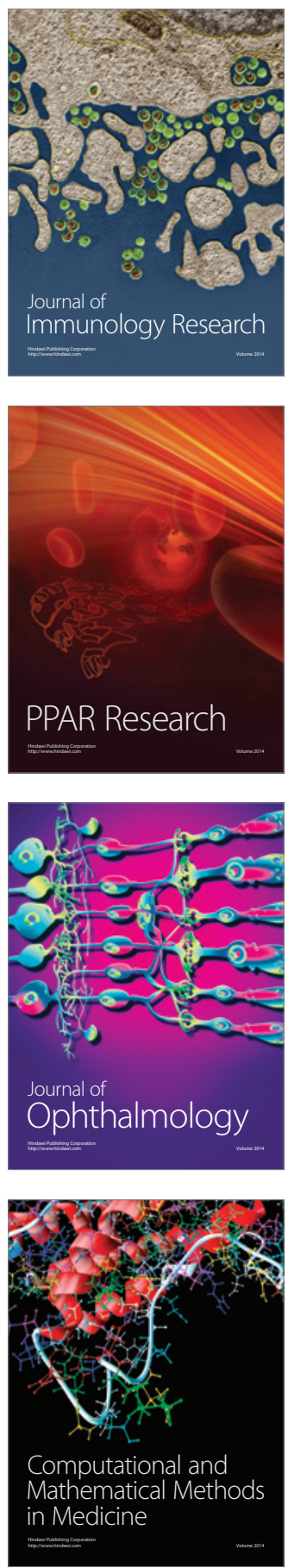

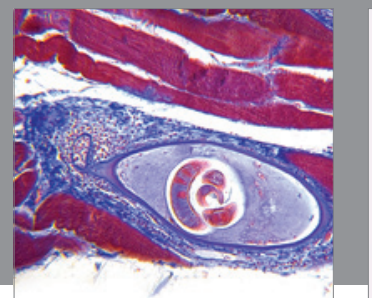

Gastroenterology

Research and Practice
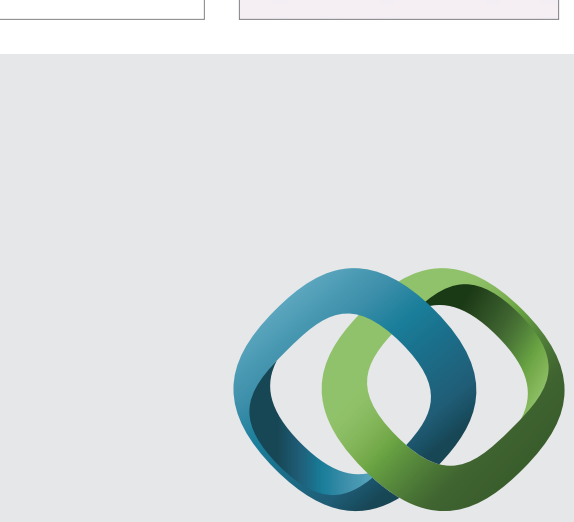

\section{Hindawi}

Submit your manuscripts at

http://www.hindawi.com
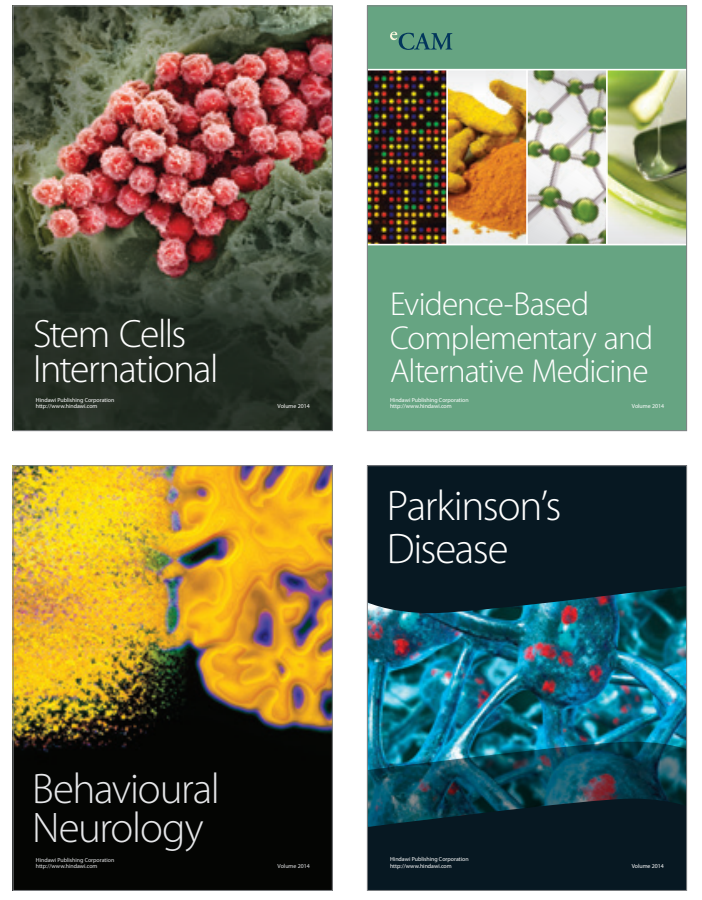
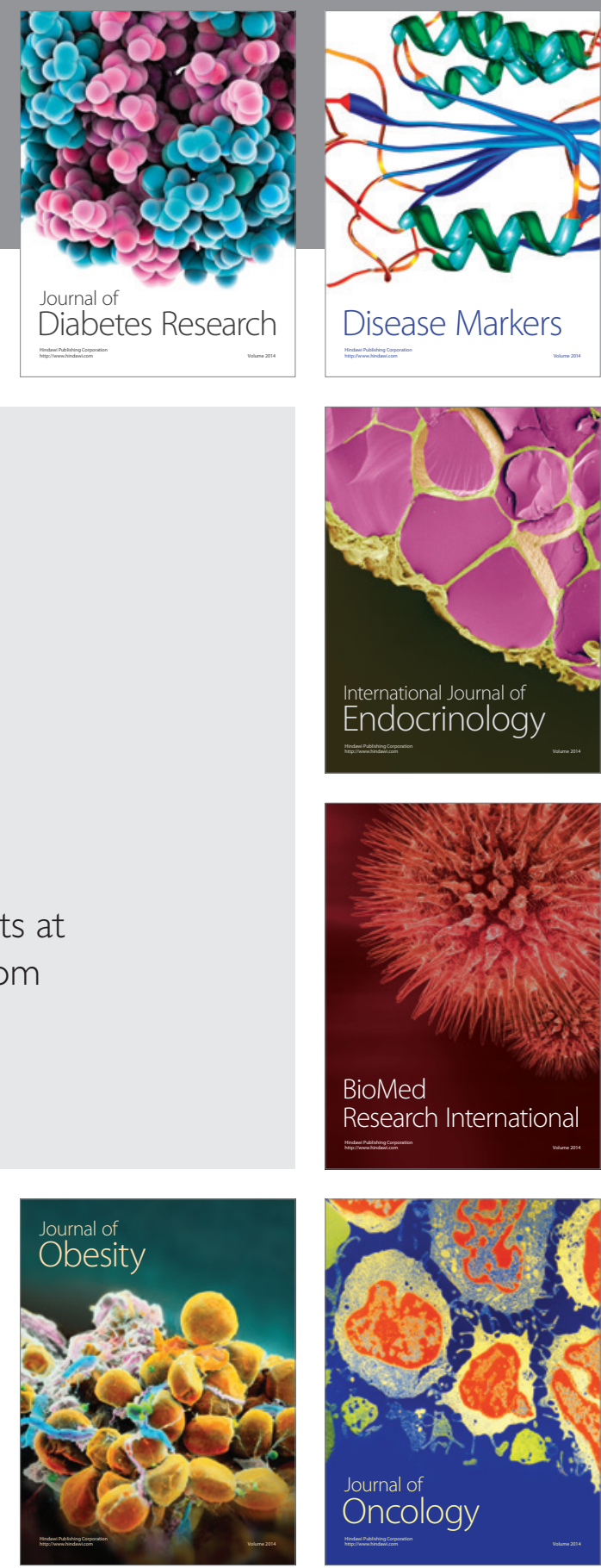

Disease Markers
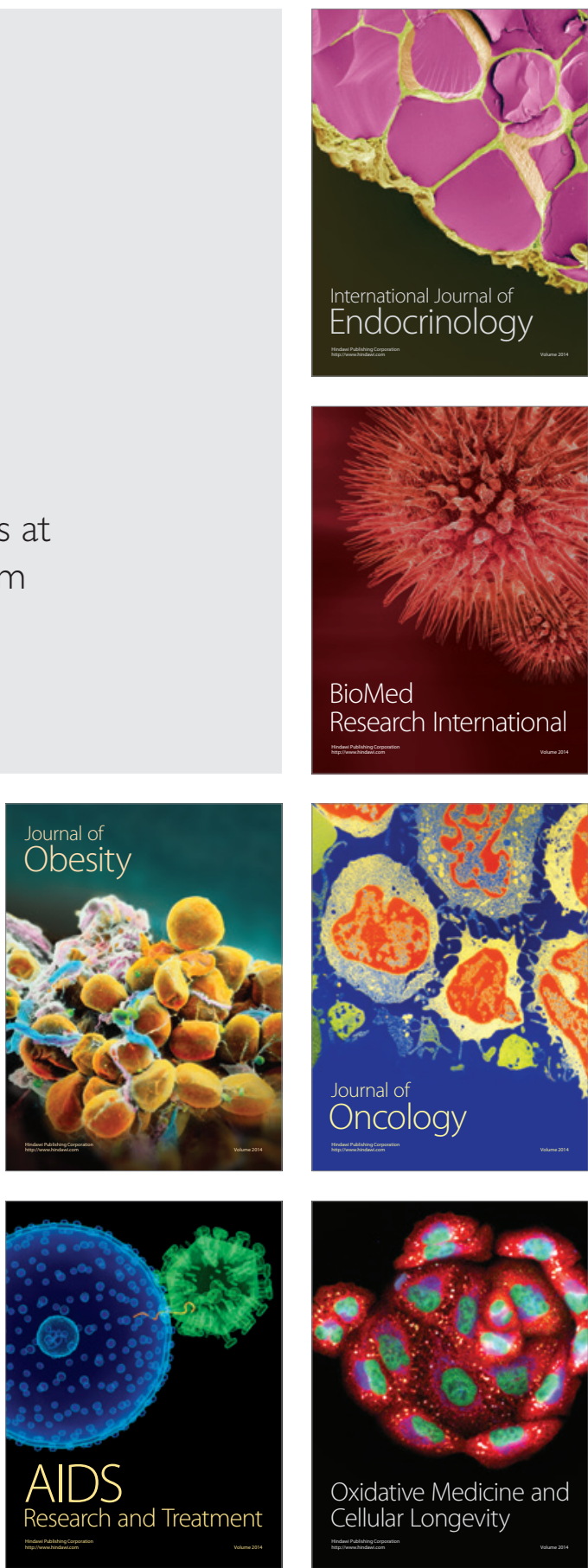